\title{
MINIMALLY INVASIVE CORONARY ARTERY BYPASS GRAFTING: THE RIB CAGE-LIFTING TECHNIQUE
}

Haldun Y. Karagoz, MD, ${ }^{\text {a }}$ Murat Kurtoglu, MD, ${ }^{\text {a }}$ Gokhan Ozerdem, MD, ${ }^{\text {a }}$ Bektas Battaloglu, MD, ${ }^{\text {a }}$ Sule Korkmaz, MD, ${ }^{\mathrm{b}}$ and Kemal Bayazit, MD, ${ }^{\mathrm{a}}$ Ankara, Turkey

Minimally invasive approaches for cardiac operations have recently gained widespread interest, albeit with some reservations. ${ }^{1-3}$ Inasmuch as the most "invasive" part of a cardiac operation is cardiopulmonary bypass (CPB), the

From the Departments of Cardiovascular Surgery a and Cardiolo-

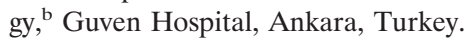

Received for publication Feb. 18, 1998; accepted for publication Feb. 25, 1998.

Address for reprints: Haldun Y. Karagoz, MD, Cankaya Cad 4/2, Cankaya, Ankara 06680, Turkey.

J Thorac Cardiovasc Surg 1998;116:354-6

Copyright (C) 1998 by Mosby, Inc.

$0022-5223 / 98 \$ 5.00+0 \quad \mathbf{1 2 / 5 4 / 8 9 9 6 2}$ principal attribute of a minimally invasive procedure should be avoidance of CPB. If this can be combined with a surgical approach that preserves chest wall integrity, a truly minimally invasive technique can be used. This report describes our initial experience with the rib cagelifting technique, in which left internal thoracic artery (LITA) to left anterior descending (LAD) coronary artery and right internal thoracic artery (RITA) to right coronary artery (RCA) anastomoses were performed without $\mathrm{CPB}$ and through the space gained by lifting the rib cage upward.

Patients and methods. Between April 1997 and September 1997, 24 patients underwent coronary artery bypass grafting with the rib cage-lifting technique. There were 22 male and two female patients whose ages ranged 


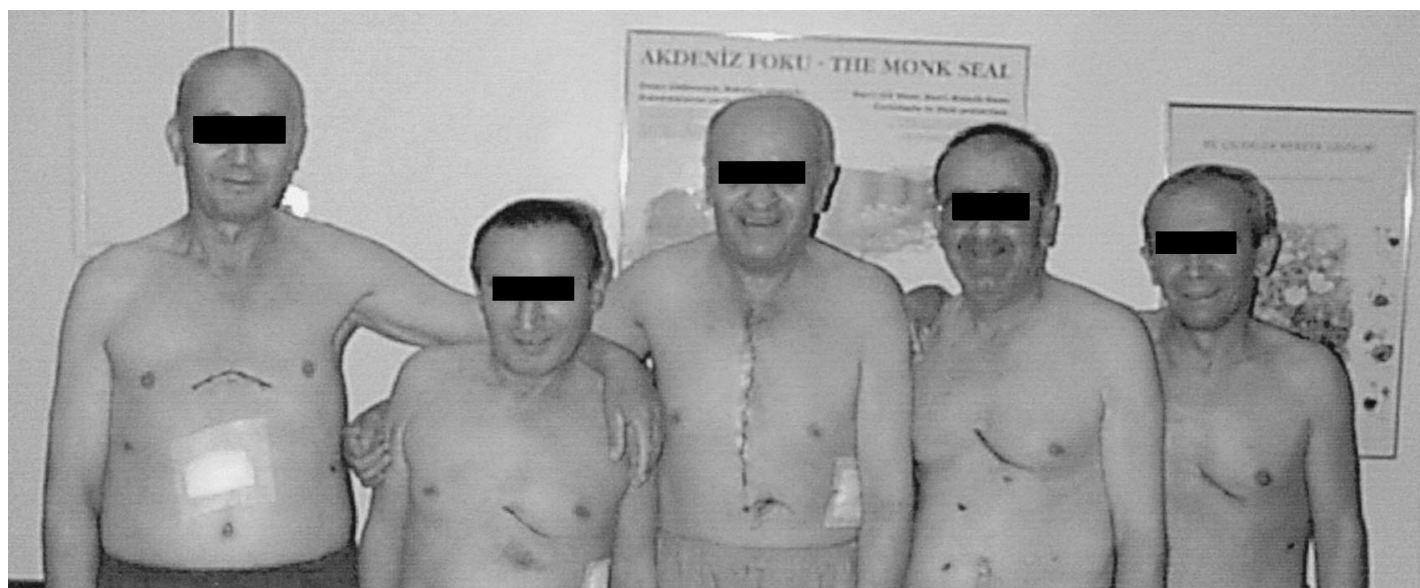

Fig. 1. Photograph from the ward showing the incisions after coronary artery operations. The patient in the middle underwent a conventional operation with a full median sternotomy. In the other patients the rib cage-lifting technique was used. Right to left, The first patient received bilateral ITA grafts, whereas patients 2, 4, and 5 received a single ITA graft.

from 32 to 67 years (mean 53.2 years). LITA-LAD bypass was performed in 21 patients, and LITA-LAD plus RITARCA bypass was performed in three patients.

PATIENT SELECTION. All patients had a critical $(>70 \%)$ proximal stenosis in the LAD artery. Three patients had additional RCA stenoses. All operations were primary procedures. Patients with associated circumflex coronary artery lesions, with multiple stenoses on the LAD artery, or with very narrow LAD arteries were not selected for this approach.

Surgical teChNique. A $7 \mathrm{~cm}$ skin incision is performed starting $1 \mathrm{~cm}$ above the level of the xiphoid process and coursing parallel and $1 \mathrm{~cm}$ above the left costal margin (Fig. 1). A few centimeters of skin are undermined above and below the incision. The linea alba is left intact and the rib cage is freed from its attachments to the rectus abdominis muscle. The rib cage is detached from the sternum by an inverted $\mathrm{J}$-shaped ministernotomy, starting from the left edge of the xiphoid process and ending at the fifth intercostal space. A single Favaloro retractor is used to lift the rib cage, pulling the rib cage toward the patient's left shoulder. Both LITA harvesting and the coronary anastomosis are performed through this space gained by lifting the rib cage with the Favaloro retractor (Fig. 2).

The LITA is harvested conventionally up to the level of the left subclavian vein. Video assistance is not required. The pericardium is opened wide. Stay sutures are placed into the left border of the pericardium and pulled upward and anteriorly through the incision. In this way the heart is elevated and the middle and distal parts of the LAD artery are exposed. A gauze sponge is placed below the acute margin of the heart to minimize heart movement. Because lifting the heart through the left pericardium is often adequate, placement of another gauze pad below or to the left of the heart is often unnecessary.

The anastomotic site is stabilized manually without the use of a stabilization device, by grasping the epicardium adjacent to the anastomotic site with tissue forceps. With two forceps, the first assistant holds and pulls upward his or her side (left) of the anastomosis just above and below the anastomotic site. From the surgeon's side (right), he or she holds the tissue with forceps in the left hand (Fig. 2 ). In this way, temporary local immobilization is achieved at the target site while the heart continues to beat. With this method, the range of movement of the target site at the time of suture placement is about $1 \mathrm{~mm}$ in every direction.

A 6 to $7 \mathrm{~mm}$ arteriotomy is performed on the LAD artery. Proximal bleeding is controlled by careful placement of a bulldog clamp on the artery along with the adjacent tissue. Back bleeding is controlled by rinsing with warm saline solution. No sutures or clamps are placed around the distal LAD to control back bleeding. The LITA-LAD anastomosis is performed with 8-0 polypropylene suture in a continuous fashion. Before the suture is tied, a 1 or $1.5 \mathrm{~mm}$ probe is passed distal and proximal to the anastomosis to relieve spasm of the LAD artery, if present.

For bilateral ITA grafting, a $10 \mathrm{~cm}$ midline transverse incision is performed parallel to and $1 \mathrm{~cm}$ above the costal arch (Fig. 1). An inferior mini-sternotomy is performed at the level of the fifth intercostal space. The ITAs are taken down with the aid of Favaloro retractors. The LITA-LAD anastomosis is performed as described earlier. For the RITA-RCA anastomosis, the heart is exposed with the use of a pediatric sternal retractor. A wide U-shaped suture buttressed with Teflon felt is placed at the acute margin of the heart and pulled toward the patient's left shoulder to expose the inferior surface of the heart. Another heavy Ushaped suture is placed around the RCA at an appropriate level and pulled caudally to expose and stabilize the RCA. Additional stabilization is achieved as described earlier. The rest of the anastomosis is performed in a conventional manner. One or two figure- 


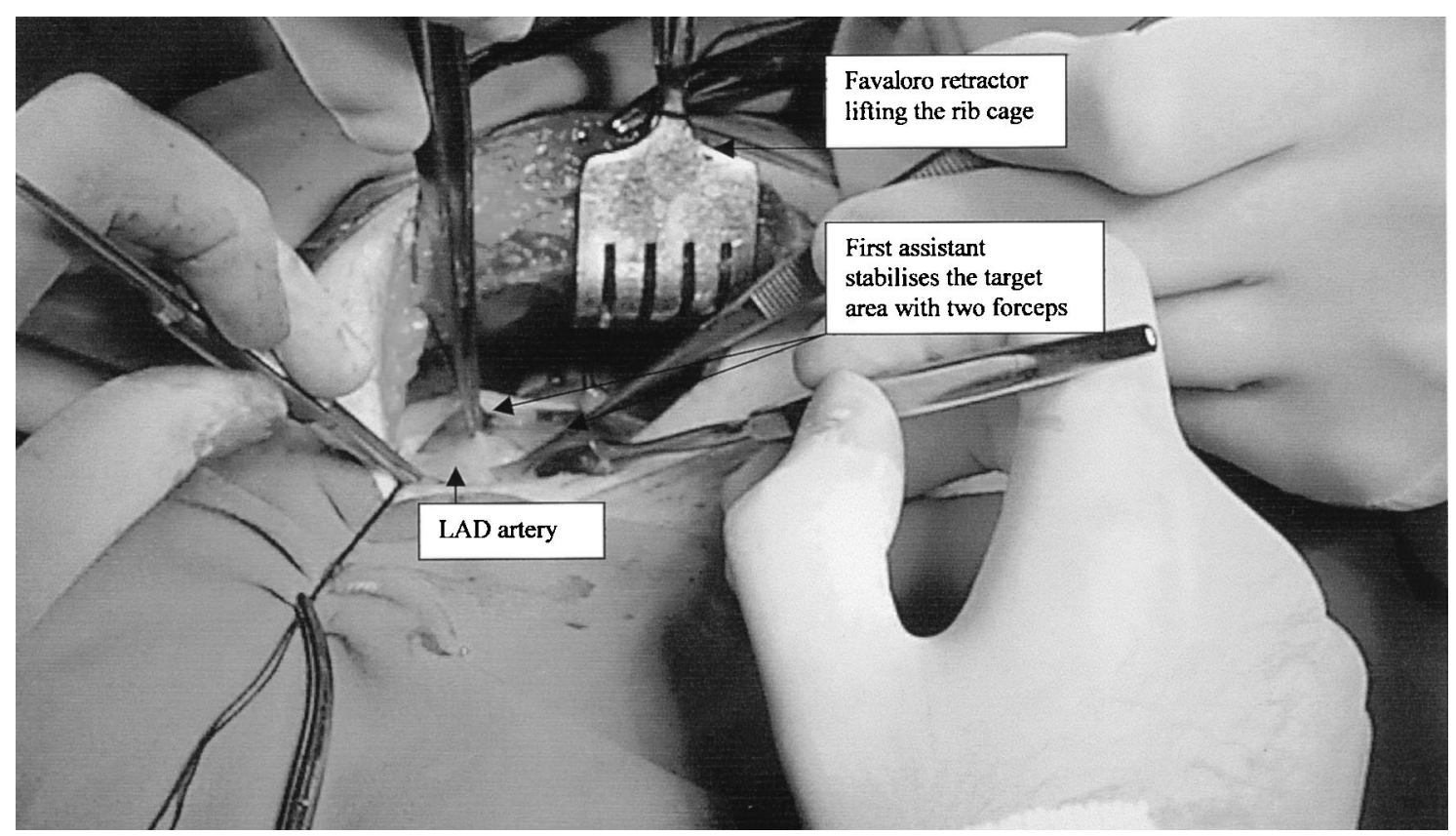

Fig. 2. Operative photograph showing the exposure and the stabilization method during coronary arteriotomy.

of-eight steel wires are used to reapproximate the rib cage to the sternum.

Pharmacologic interventions to slow the heart rate or temporarily stop the heart are often not required. Rarely, intravenous injections of metoprolol in $2.5 \mathrm{mg}$ doses or isoflurane inhalations are used to decrease the heart rate and contractility.

Results. Total operation time was $69 \pm 12$ minutes for the patients having LITA-LAD grafting and $126 \pm 9$ minutes for those having bilateral ITA grafting. The ITA-coronary artery anastomoses took 6 to 10 minutes to construct (mean $7.2 \pm 0.9$ minutes). Patients were extubated in the intensive care unit after hemodynamic stabilization was confirmed (mean length of intubation time including the operation was $196 \pm 33$ minutes). Patients stayed in the intensive care unit overnight (mean $16 \pm 3$ hours). Mean amount of mediastinal drainage was $255 \pm$ $25 \mathrm{ml}$. No blood transfusions were needed, and no operative morbidity or deaths occurred. Mean hospital discharge time was $3 \pm 1$ days.

All patients underwent a follow-up coronary angiogram, 13 before hospital discharge and 11 during the second postoperative month. Graft patency rate was $100 \%$ in 27 anastomoses.

All patients were contacted during the second and fourth postoperative months. All were symptom-free, and 16 of 17 employed patients were working full time in the second postoperative month. Mean length of postoperative time without working was $19 \pm 3$ days in nine patients who work for themselves and exactly 60 days in seven patients in government service. One patient had retired from working.

Discussion. A minimally invasive approach should not compromise the reliability of the cardiac repair; that is, a standard or perfect operation should be performed. More- over, it should not violate chest wall integrity to a great extent and create anatomic defects such as rib resections, and it should avoid CPB if possible. The rib cage-lifting technique fulfills these criteria and also offers several advantages over the commonly used minithoracotomy type operations. The primary advantage of the rib cage-lifting approach is that, owing to the generous space gained by lifting the rib cage upward, a perfectly harvested ITA graft can be perfectly anastomosed to the usual site on the LAD artery. In contrast, in the minithoracotomy type operations the site of the anastomosis is often dictated by the location of the small window. The presented stabilization technique avoids the use of cumbersome devices through an already small incision. The technique also avoids sutures or intravascular devices to control bleeding, which may cause vessel injury. ${ }^{4}$ The rib cage-lifting approach yields superior cosmetic results and is reasonably painless, and the early results are encouraging. However, it is a technically demanding procedure and requires considerable experience in performing coronary anastomoses on the beating heart.

\section{REFERENCES}

1. Lytle BW. Minimally invasive cardiac surgery. J Thorac Cardiovasc Surg 1996;111:554-5.

2. Westaby S, Benetti FJ. Less invasive coronary surgery: consensus from the Oxford meeting. Ann Thorac Surg 1996;62:924-31.

3. Elbeery JR, Chitwood WR Jr. Minimally invasive cardiac surgery: heart surgery for the 21 st century. N C Med J 1997;58:374-7

4. Alessandrini F, Gaudino M, Glieca F, Luciani N, Piancone $\mathrm{FL}$, Zimarino $\mathrm{M}$, et al. Lesions of the target vessel during minimally invasive myocardial revascularization. Ann Thorac Surg 1997;64:1349-53. 